\title{
ORIGINAL
}

\section{Past infections are associated with low levels of anti-citrullinated protein autoantibodies in rheumatoid arthritis}

\author{
Kenji Tani', Minaho Kanamori',3, Yutaro Nagase ${ }^{2,3}$, Yoshihiro Okura1', Shingo Kawaminami ${ }^{3}$, Keisuke Kawahito ${ }^{4}$, \\ Keisuke Inaba ${ }^{5}$, Kaori Inaba ${ }^{6}$, Akiko Miyatake ${ }^{7}$, Keisuke Kondo ${ }^{3}$, Ryo Tabata ${ }^{3}$, Yoshihiro Suzuki ${ }^{3}$, \\ and Harutaka Yamaguchi ${ }^{3}$ \\ ${ }^{1}$ General Medicine and Primary Care, Tokushima University Hospital, Tokushima, Japan, ${ }^{2}$ Student Lab, The University of Tokushima Faculty \\ of Medicine, Tokushima, Japan, ${ }^{3}$ Department of General Medicine, Institute of Biomedical Sciences, The University of Tokushima Gradu- \\ ate School, Tokushima, Japan, ${ }^{4}$ Kaifu Tokushima Prefectural Hospital, Tokushima, Japan, ${ }^{5}$ Yoshinogawa Medical Center, Tokushima, Japan, \\ ${ }^{6}$ Tokushima Prefectural Central Hospital, Tokushima, Japan, ${ }^{7}$ Yamakami Hospital, Tokushima, Japan
}

\begin{abstract}
Background : Rheumatoid arthritis (RA), an autoimmune disease of unknown etiology, is believed to occur as the result of actions of genetic and environmental factors. In this study, we examined the relation of past histories about infectious diseases with the levels anti-citrullinated protein autoantibodies (ACPA) in RA. Methods : Results of a questionnaire about histories of infectious diseases were obtained from 85 patients with RA, and were analyzed. Results : Significantly lower level of ACPA was detected in patients with the history of tonsillitis, otitis media or urinary cystitis than in those without it. There was no difference in the level of ACPA in RA patients between with and without cold / influenza, rubella, chickenpox, herpes labialis or herpes zoster. When RA patients were divided into two groups, high-level and low-level ACPA, multiple logistic regression analysis revealed that the history of otitis media was a significantly independent factor for the low level of ACPA. There was no significant relation between the level of rheumatoid factor and histories of infectious diseases. Conclusion : This study clarified that the past history of otitis media is associated with the low level of ACPA in RA. J. Med. Invest. 67 :182-188, February, 2020
\end{abstract}

Keywords : rheumatoid arthritis, ACPA, environmental factor, infection, bacteria

\section{INTRODUCTION}

Rheumatoid arthritis (RA) is an autoimmune disease characterized by destructive synovial joint inflammation leading to substantial joint damage, deformity, and functional disability, occasionally with systemic involvement $(1,2)$. The cause of RA is unknown, but several genetic and epidemiological studies suggest the importance of complex interactions between genetic, environmental and hormonal factors, and the immune system $(3,4)$. There is a preclinical period in the development of RA where the genetic and environmental factors interact to initiate and propagate the autoimmune process (5). Associations between RA and various environmental factors have been studied, but the evidence to show a causal role of the factors is inconclusive $(3,4)$. Infectious diseases are the major environmental exposure that is considered as an initiator and a risk factor for the development of RA (6), but the mechanism is not fully clarified.

There are reliable biomarkers for RA to know to be used for getting early diagnosis, assessing prognosis and achieving a better disease management (7). Autoantibodies most commonly used as an aid for diagnosing/classifying RA are rheumatoid factor (RF) and anti-citrullinated protein autoantibodies (ACPA), and their importance was recently emphasized by the inclusion of ACPA and RF on ACR/EULAR 2010 RA diagnostic criteria (8). In comparison with RF, ACPA have higher sensitivity and specificity for RA showing better diagnostic value (9).

Received for publication November 7, 2019 ; accepted March 17, 2020.

Address correspondence and reprint requests to Kenji Tani, M.D., General Medicine and Primary Care, Tokushima University Hospital, 50 Kuramoto-cho 2, Tokushima 770-8503, Japan and Fax : +81-88-633-9687.
Moreover, several reports have shown that ACPA are the poor prognostic factor of joint destruction, and have an etiological role in RA development (10). ACPA-positive and ACPA-negative RA have different risk factors and pathogenic pathways (11).

In this study, we examined histories about infectious diseases using a questionnaire to patients with RA, and revealed that past infectious diseases were associated with low levels of ACPA in RA.

\section{METHODS}

\section{Questionnaires}

The questionnaire was given to patients with RA between June and October in 2018. Table 1 shows a list of questionnaire entries which consists of questions about backgrounds of patients and histories of infectious diseases. Q1) smoking status (current smokers / ever or never smokers), Q2) passive smoking status (yes / no), Q3) sleeping time a day ( $<6 \mathrm{~h} / 6-8 \mathrm{~h} />8 \mathrm{~h}), \mathrm{Q} 4)$ constipation (severe / mild / no), Q5) manual labor work (yes or ever / never), Q6) past history of bone fracture (yes / no), Q7) past history of a trauma except bone fracture (yes / no), Q8) periodontitis (present / absent) : Five questions about periodontitis were performed to the patient. If the number of yes was $\geq 3$ of five, the patient was divided into a group of "present". If the number of yes was $\leq 2$ of 5 , the patient was into a group of "absent", Q9) experience of otitis media, rubella, chickenpox, herpes labialis, or herpes zoster (yes / no), Q10) Frequency of cold/influenza, tonsillitis, or urinary cystitis (sometimes / rare) : If the frequency was $\geq$ once per several years, the patient was divided into a group of "sometimes". If the frequency was < once per several years, the patient was into a group of "rare". 
Table 1. questionnaire entries

\begin{tabular}{|c|c|c|c|c|c|}
\hline Questions & \multicolumn{5}{|c|}{ Answers } \\
\hline Q1) Smoking: Have you smoked? & current & & I & & no or quit \\
\hline Q2) Passive smoking: Is there anyone who smokes in your house? & yes & & I & & no \\
\hline Q3) Sleeping time a day : How long are your average sleeping hours? & $<6 \mathrm{~h}$ & I & $6-8 \mathrm{~h}$ & I & $>8 \mathrm{~h}$ \\
\hline Q4) Constipation : Are you constipated? & severe & l & mild & I & no \\
\hline Q5) Manual labor work: Have you engaged in a manual labor work? & current or ever & & I & & never \\
\hline Q6) Bone fracture : Have you got a bone fracture? & yes & & I & & no \\
\hline Q7) Trauma except bone fracture: Have you got a trauma except bone fracture? & yes & & I & & no \\
\hline $\begin{array}{l}\text { Q8) Periodontitis : Have you been diagnosed with the periodontitis by a dentist? } \\
\text { Do you have gums with swelling? } \\
\text { Do you have gums with bleeding? } \\
\text { Do you feel pain in gums when biting something solid? } \\
\text { Do you have any loose teeth? }\end{array}$ & present* & & I & & absent* \\
\hline $\begin{array}{l}\text { Q9) Experience of infectious diseases : Have you got otitis media, infections of rubella, } \\
\text { chickenpox, herpes labialis, or herpes zoster? }\end{array}$ & yes & & I & & no \\
\hline $\begin{array}{l}\text { Q10) Frequency of infectious diseases : How often have you got a cold/influenza, tonsillitis, } \\
\text { or urinary cystitis? }\end{array}$ & sometimes** & & I & & $\operatorname{rare}^{* *}$ \\
\hline
\end{tabular}

* Present; the number of yes $\geq$ three of 5 , absent ; the number of yes $\leq$ two of 5 .

$* *$ Sometimes ; frequency $\geq$ once per several years, rare ; frequency $\leq$ once per several years.

\section{Patients}

The present study was conducted at Tokushima Prefectural Kaifu Hospital and Toyo Hospital which are the professional hospitals for RA medical treatment. RA was diagnosed according to the 1987 American College of Rheumatology classification criteria for RA (12) or ACR/EULAR 2010 RA criteria (8). We enrolled patients with RA who were treated in the hospitals (Table 2). We handed over the questionnaire directly to $145 \mathrm{pa}-$ tients with RA in the hospitals, and a participation rate was 58.6 $\%$ (85 patients). Data of anti-cyclic citrullinated peptide (CCP) antibodies (ACPA), RF, matrix metalloproteinase (MMP)-3 and c-reactive protein (CRP) were collected from medical records of RA patients at diagnosis as RA. We did not have records on anti-CCP antibodies when cases were diagnosed prior to its widespread use. The abnormal levels of anti-CCP antibodies, $\mathrm{RF}$ and $\mathrm{CRP}$ were defined as $\geq 4.5 \mathrm{U} / \mathrm{ml},>20 \mathrm{IU} / \mathrm{ml},>0.3$ $\mathrm{mg} / \mathrm{dl}$, respectively. The abnormal MMP-3 level was defined as $>121.0 \mathrm{ng} / \mathrm{ml}$ for men and $>59.7 \mathrm{ng} / \mathrm{ml}$ for women. When data of anti-CCP antibodies, $\mathrm{RF}$ and CRP were under the sensitivity level, the data of the detection limit were used (anti-CCP antibodies $=0.5 \mathrm{U} / \mathrm{ml}, \mathrm{RF}=4 \mathrm{IU} / \mathrm{ml}, \mathrm{CRP}=0.05 \mathrm{mg} / \mathrm{ml})$.

\section{Statistical analysis}

Comparison between groups was made using Mann-Whitney $\mathrm{U}$ test for continuous variables and Pearson's chi-squared test or Fisher's exact test for categorical variables. Median values were calculated for non-normally distributed continuous variables. Data were mainly presented as median and $25^{\text {th }}-75^{\text {th }}$ quarter, count and percentage, or odds ratio (OR) and 95\% confidence interval (CI). Multivariate logistic regression analyses were performed with stepwise selection to determine variables related to the level of ACPA. Spearman rank correlation coefficient was used to examine the correlation between parameters. The results were regarded as significant when $p$ value was $<0.05$. All statistical analyses were performed using IBM SPSS statistics version 24 software (Chicago, IL, USA).

Table 2. Characteristics and laboratory data of patients with RA

\begin{tabular}{cccc}
\hline & $\mathrm{n}(\%)$ & Normal range & Variables \\
\hline Age (y) & 85 & & $68(62.5-74.5)$ \\
Sex (male : female) & 85 & & $17(20 \%): 68(80 \%)$ \\
Age at diagnosis (y) & 85 & & $60(51-66)$ \\
Disease duration (y) & 85 & $<4.5$ & $7(3.5-12)$ \\
Anti-CCP antibody (U/ml) & $55(64.7)$ & $\leq 20$ & $62.4(8.8-236.0)$ \\
RF (IU/ml) & $75(88.2)$ & & $49.4(19.6-138.4)$ \\
MMP-3 (ng/dl) & $34(40.0)$ & Male $; \leq 121.0$ Female $; \leq 59.7$ & $91.9(44.6-173.7)$ \\
CRP $(\mathrm{mg} / \mathrm{dl})$ & $79(92.9)$ & $\leq 0.3$ & $0.58(0.15-1.67)$ \\
\hline
\end{tabular}

Data of anti-cyclic citrullinated peptide (CCP) antibody (ACPA), rheumatoid factor (RF), matrix metalloprotein ase (MMP)-3 and c-reactive protein (CRP) were collected from medical records at diagnosis as RA. Values are presented as number (percentages) and median (interquartile range). 


\section{RESULTS}

\section{Patient characteristics and laboratory data}

Table 2 shows the summary of patient characteristics at the time of study enrollment and laboratory data at diagnosis as RA. Eighty five patients with RA who returned us the questionnaire were included in this study. Patients consisted of 17 male (20\%) and $68(80 \%)$ female with median age of 68 (62.5-74.5) years old. The median age at diagnosis was 60 (51-66) years old, and the disease duration was 7 (3.5-12) years. As biomarkers, the absolute values of anti-cyclic citrullinated peptide (anti-CCP) antibodies (ACPA), rheumatoid factor (RF), matrix metalloproteinase (MMP)-3 and c-reactive protein (CRP) were obtained at diagnosis as RA by reviewing patients' medical records in 55 (64.7\%), 75 (88.2\%), 34 (30.0\%), and 79 (92.9\%), respectively, of 85 patients. Since the test of anti-CCP antibodies for the diagnosis of RA was covered by insurance in Apr, 2007 in Japan more recently than $\mathrm{RF}$, they could not be measured for patients who were diagnosed as RA before the time. That is the reason for low percentages observed in anti-CCP antibodies when compared with RF.

\section{Comparison of the level of ACPA among clinical findings}

The level of ACPA was compared among various clinical findings. There were no significant differences in the level of ACPA between two groups in terms of age at diagnosis or sex (Table 3). No difference in the level of ACPA was detected in the status of smoking, passive smoking, sleeping time, constipation, the working history of manual labor, past history of bone fracture or that of trauma. In female patients, there was no difference in the level of ACPA between two groups of the experience of pregnancy, times of giving birth, or the experience of breast feeding (data not shown).

\section{Comparison of the level of ACPA in histories of infectious diseases}

The level of ACPA was compared in present status and past histories of infectious diseases (Table 4). Significantly lower level of ACPA was detected in patients with the history of tonsillitis $(p=0.038)$, otitis media $(p=0.003)$ or urinary cystitis $(p=0.043)$ than in those without it. Although patients with the history of mycoplasma pneumonia showed significantly lower ACPA than those without it, the number of patients with mycoplasma pneumonia history is a few (3 patients). There was no difference in the level of ACPA between two groups of present status of periodontitis, or the history of cold/influenza, rubella, chickenpox, herpes labialis or herpes zoster.

Comparison of histories of infectious diseases between patients with high and low ACPA

According to the 2010 ACR/EULAR criteris (8) in which a level of $>$ three times of the normal upper limit value is considered to be high-level positive, the level of ACPA was divided into two groups, high ACPA and low ACPA, by $13.5 \mathrm{U} / \mathrm{ml}$, in this study, and the characteristic of histories of infectious diseases

Table 3. Comparison of ACPA levels with backgrounds and clinical findings of patients with RA

\begin{tabular}{|c|c|c|c|c|c|c|}
\hline Clinical findings & & & $\operatorname{ACPA}(\mathrm{U} / \mathrm{ml}, \mathrm{n}=55)$ & & & $\mathrm{p}$ value \\
\hline Age at diagnosis (y) $(\geq$ median $/<$ median) & $56.9(11.2-320.2) \mathrm{n}=34$ & & I & & $74.9(7.4-212.0) \mathrm{n}=21$ & 0.775 \\
\hline Male / female & $48.6(9.2-286.7) \mathrm{n}=13$ & & l & & $62.4(7.4-251.3) \mathrm{n}=41$ & 0.946 \\
\hline Smoking (current / no or quit) & $31.0(13.5-135.8) \mathrm{n}=13$ & & l & & $74.9(7.4-359.2) \mathrm{n}=41$ & 0.430 \\
\hline Passive smoking (yes / no) & $75.8(7.2-173.6) \mathrm{n}=8$ & & l & & $56.9(8.1-320.2) \mathrm{n}=46$ & 0.971 \\
\hline Sleeping time $(<6 \mathrm{~h} / 6-8 \mathrm{~h} />8 \mathrm{~h})$ & $16.4(3.3-221.5) \mathrm{n}=5$ & I & $73.5(2.1-184.7) \mathrm{n}=20$ & / & $74.9(21.9-326.0) \mathrm{n}=29$ & 0.866 \\
\hline Constipation (severe / mild / no) & $33.0(2.1-219.9) \mathrm{n}=20$ & I & $74.9(17.0-251.3) \mathrm{n}=29$ & I & $48.6(4.7-1322.9) \mathrm{n}=5$ & 0.504 \\
\hline Manual labor (current or ever / never) & $62.4(0.9-403.8) n=11$ & & l & & $51.4(8.8-188.0) \mathrm{n}=43$ & 0.807 \\
\hline Bone fracture (yes / no) & $61.8(4.0-255.6) \mathrm{n}=26$ & & l & & $56.9(14.1-300.1) n=28$ & 0.631 \\
\hline Trauma (yes / no) & $100.0(4.7-1161.8) \mathrm{n}=5$ & & l & & $51.4(9.7-275.3) \mathrm{n}=49$ & 0.815 \\
\hline
\end{tabular}

The level of ACPA is compared among clinical findings of patients with RA. Values are presented as median (interquartile range).

Table 4. Comparison of ACPA levels with histories of infectious diseases

\begin{tabular}{ccccc}
\hline Infectious diseases & \multicolumn{2}{c}{ ACPA (U/ml) } & p value \\
\hline Periodontitis (present / absent) & $51.4(16.4-403.8) \mathrm{n}=11$ & $/$ & $50.6(1.2-188.0) \mathrm{n}=41$ & 0.530 \\
Cold \& influenza (sometimes / rare) & $42.4(2.4-98.4) \mathrm{n}=17$ & $/$ & $87.5(7.8-404.5) \mathrm{n}=36$ & 0.331 \\
Tonsillitis (sometimes / rare) & $17.5(0.6-87.2) \mathrm{n}=14$ & $/$ & $95.5(14.9-416.3) \mathrm{n}=38$ & 0.038 \\
Otitis media (yes / no) & $3.1(0.7-59.7) \mathrm{n}=13$ & $/$ & $100.0(17.2-411.5) \mathrm{n}=40$ & 0.003 \\
Urinary cystitis (sometimes / rare) & $26.5(0.9-417.1) \mathrm{n}=14$ & $/$ & $99.4(14.9-372.1) \mathrm{n}=41$ & 0.043 \\
Mycoplasma pneumonia (yes / no) & $0.5(0.0-$ ) $\mathrm{n}=3$ & $/$ & $62.4(8.8-337.4) \mathrm{n}=50$ & 0.020 \\
Rubella (yes / no) & $74.9(12.6-1081.5) \mathrm{n}=13$ & $/$ & $74.9(16.4-439.2) \mathrm{n}=39$ & 0.363 \\
Chickenpox (yes / no) & $63.2(14.5-760.3) \mathrm{n}=14$ & $/$ & $63.2(2.1-279.6) \mathrm{n}=39$ & 0.552 \\
Herpes labialis (yes / no) & $439.2(1.2-1723.7) \mathrm{n}=7$ & $/$ & $50.6(6.0-174.8) \mathrm{n}=46$ & 0.319 \\
Herpes zoster (yes / no) & $48.6(6.0-100.0) \mathrm{n}=8$ & $/$ & $62.4(4.9-337.4) \mathrm{n}=45$ & 0.971 \\
\hline
\end{tabular}

The level of ACPA is compared between presence of periodontitis and histories of infectious diseases. Values are presented as median (interquartile range). 
was compared between the two groups (Table 5). Patients with the history of otitis media were significantly $(p=0.019)$ more in the low ACPA group. There was no difference in the two groups of present status of periodontitis, or past histories of cold/influenza, tonsillitis, urinary cystitis, mycoplasma pneumonia, rubella, chickenpox, herpes labialis or herpes zoster between high and low ACPA groups.

We next performed multiple logistic regression analysis to compare the relative impact of the variables. Candidate variables, tonsillitis, otitis media and urinary cystitis, were selected based on statistical significance in results shown in Tables 4 and 5 , and were analyzed as dependent variables, along with age at diagnosis and sex, by using a stepwise backward selection method. The analysis revealed that the history of otitis media $(p=0.015 ; \mathrm{OR}=0.179 ; 95 \% \mathrm{CI}=0.045-0.713)$ was a significant ly independent factor for the low level of ACPA, but the history of tonsillitis $(\mathrm{p}=0.730 ; \mathrm{OR}=0.768 ; 95 \% \mathrm{CI}=0.171-3.445)$ or urinary cystitis $(\mathrm{p}=0.346 ; \mathrm{OR}=0.512 ; 95 \% \mathrm{CI}=0.127-2.060)$ was not significant (Table 6). Spearman rank correlation coefficient showed that among otitis media, urinary cystitis and tonsillitis there is a significant correlation between otitis media and tonsillitis $(\mathrm{r}=0.315, \mathrm{p}=0.004)$.

Considerable high levels of ACPA $(>100 \mathrm{U} / \mathrm{ml}$ ) were observed in none of patients with histories of otitis media ( $0 \%, 0$ of 13) (vs. without those of otitis media $(55.0 \%, 22$ of 40$), p<0.001)$, and were observed in $21.4 \%$ (3 of 14) patients with those of tonsillitis (vs. without those of tonsillitis $(50.0 \%, 19$ of 38$), p=0.064)$ and were observed in $21.4 \%$ (3 of 14) of patients with those of urinary cystitis (vs. without those of urinary cystitis $(51.2 \%, 21$ of 41$), p=0.052)$.

The relation of the past history of tonsillitis, otitis media or urinary cystitis and serum biomarkers of $R A$

The relation of histories of otitis media, tonsillitis, or urinary cystitis with the values of serum biomarkers of RA was examined (Table 7). Significantly low levels in patients with tonsillitis, otitis media, or urinary cystitis when compared with in those without it were detected in ACPA, but not in RF, MMP-3, or CRP.

\section{DISCUSSION}

This study demonstrates significantly lower level of ACPA in RA patients with the past history of tonsillitis, otitis media, or urinary cystitis than in those without it. These are unexpected observations to us because infectious diseases have been shown to be related to the development of RA $(3,5)$. Our results showed that past histories of viral infections such as cold/influenza, rubella, chickenpox, or herpes did not affect the level of ACPA, suggesting that bacterial infections are associated with the decreased level of ACPA.

Multiple logistic regression analysis using tonsillitis, otitis media and urinary cystitis as dependent variables revealed that

Table 5. Comparison of histories of infectious diseases between patients with high ACPA and low ACPA

\begin{tabular}{|c|c|c|c|c|c|}
\hline & High ACPA & Low ACPA & $\mathrm{p}$ value & OR & $95 \% \mathrm{CI}$ \\
\hline Periodontitis (present / absent) & $9 / 28$ & $2 / 13$ & 0.379 & 2.089 & $0.394-11.070$ \\
\hline Cold / influenza (sometimes / rare) & $12 / 26$ & $5 / 10$ & 0.902 & 0.923 & $0.258-3.297$ \\
\hline Tonsillitis (sometimes / rare) & $8 / 29$ & $6 / 9$ & 0.176 & 0.414 & $0.113-1.512$ \\
\hline Otitis media (yes / no) & $6 / 32$ & $7 / 8$ & 0.019 & 0.214 & 0.056-0.816 \\
\hline Urinary cystitis (sometimes / rare) & $8 / 32$ & $6 / 9$ & 0.129 & 0.375 & $0.103-1.364$ \\
\hline Mycoplasma pneumonia (yes / no) & $1 / 37$ & $2 / 13$ & 0.129 & 0.176 & $0.015-2.102$ \\
\hline Rubella (yes / no) & $10 / 27$ & $3 / 12$ & 0.596 & 1.481 & 0.345-6.369 \\
\hline Chickenpox (yes / no) & $11 / 27$ & $3 / 12$ & 0.506 & 1.630 & $0.384-6.922$ \\
\hline Herpes labialis (yes / no) & $4 / 34$ & $3 / 12$ & 0.359 & 0.471 & $0.092-2.414$ \\
\hline Herpes zoster (yes / no) & $6 / 32$ & $2 / 13$ & 0.822 & 1.219 & $0.217-6.842$ \\
\hline
\end{tabular}

Patients with RA were divided into two groups, high and low, by a level of three times of the normal upper limit of ACPA (13.5 U/ml). Pearson's chi-squared test or Fisher's exact test was performed to determine the relation between infectious diseases and the level of ACPA. OR ; odds ratio, $95 \%$ CI ; $95 \%$ confidence interval.

Table 6. Multivariate logistic regression analysis for strength of association between infectious diseases and the level of ACPA

\begin{tabular}{cccc}
\hline & OR & $95 \%$ CI & $p$ \\
\hline Age at diagnosis & 0.992 & $0.932-1.056$ & 0.799 \\
Sex & 0.734 & $0.135-3.999$ & 0.721 \\
Tonsillitis & 0.768 & $0.171-3.445$ & 0.730 \\
Otitis media & 0.179 & $0.045-0.713$ & 0.015 \\
Urinary cystitis & 0.512 & $0.127-2.060$ & 0.346 \\
\hline
\end{tabular}

Patients with RA were divided into two groups, high and low, by a level of three times of the normal upper limit of ACPA (13.5 U/ml). Multivariate logistic regression analyses were performed to determine the strength of association between infectious diseases and the level of ACPA. OR; odds ratio, 95\% CI; $95 \%$ confidence interval. 
Table 7. The relation of serum markers of RA with past histories of infectious diseases

\begin{tabular}{|c|c|c|c|c|c|c|c|c|c|}
\hline \multirow{2}{*}{ Markers } & \multicolumn{3}{|c|}{ Tonsillitis } & \multicolumn{3}{|c|}{ Otitis media } & \multicolumn{3}{|c|}{ Urinary cystitis } \\
\hline & Sometimes & Rare & $\mathrm{p}$ value & Yes & No & $\mathrm{p}$ value & Sometimes & Rare & $p$ value \\
\hline $\operatorname{ACPA}(\mathrm{U} / \mathrm{ml})$ & $\begin{array}{c}74.9 \\
(0.6-137.4)\end{array}$ & $\begin{array}{c}95.5 \\
(9.7-179.8)\end{array}$ & 0.038 & $\begin{array}{c}4.9 \\
(2.8-50.2)\end{array}$ & $\begin{array}{c}100.0 \\
(13.3-174.8)\end{array}$ & 0.003 & $\begin{array}{c}6.0 \\
(2.7-63.5)\end{array}$ & $\begin{array}{c}100.0 \\
(21.6-181.4)\end{array}$ & 0.043 \\
\hline $\mathrm{RF}(\mathrm{IU} / \mathrm{ml})$ & $\begin{array}{c}57.0 \\
(18.0-258.4)\end{array}$ & $\begin{array}{c}40.0 \\
(23.2-174.5)\end{array}$ & 0.794 & $\begin{array}{c}24.0 \\
(13.0-52.0)\end{array}$ & $\begin{array}{c}49.5 \\
(31.0-211.0)\end{array}$ & 0.749 & $\begin{array}{c}59.0 \\
(37.0-94.9)\end{array}$ & $\begin{array}{c}32.0 \\
(21.0-309.0)\end{array}$ & 0.397 \\
\hline MMP-3 (ng/dl) & $\begin{array}{c}44.4 \\
(38.4-82.2)\end{array}$ & $\begin{array}{c}78.9 \\
(45.7-108.8)\end{array}$ & 0.349 & $\begin{array}{c}46.7 \\
(43.7-75.3)\end{array}$ & $\begin{array}{c}68.4 \\
(44.7-108.8)\end{array}$ & 0.374 & $\begin{array}{c}57.9 \\
(43.0-133.6)\end{array}$ & $\begin{array}{c}52.7 \\
(42.7-107.7)\end{array}$ & 0.753 \\
\hline $\mathrm{CRP}$ (mg/dl) & $\begin{array}{c}0.18 \\
(0.11-0.58)\end{array}$ & $\begin{array}{c}0.45 \\
(0.13-1.78)\end{array}$ & 0.602 & $\begin{array}{c}0.07 \\
(0.06-1.08)\end{array}$ & $\begin{array}{c}0.25 \\
(0.15-0.82)\end{array}$ & 0.680 & $\begin{array}{c}0.20 \\
(0.19-4.34)\end{array}$ & $\begin{array}{c}0.29 \\
(0.13-0.90)\end{array}$ & 0.952 \\
\hline
\end{tabular}

Data of anti-cyclic citrullinated peptide (CCP) antibody (ACPA), rheumatoid factor (RF), matrix metalloproteinase (MMP)-3 and c-reactive protein (CRP) were collected from medical records at diagnosis as RA. Values are presented as median (interquartile range).

the history of otitis media was a significantly independent factor for the low level of ACPA, but no significance for the low ACPA was detected in the history of tonsillitis or urinary cystitis. Tonsillitis and otitis media are known to be clinically often complicated. Since Spearman rank correlation coefficient showed that there is a significant correlation between past histories of tonsillitis and otitis media, multicollinearity may affect the result. Some antibiotics such as minocycline are known to have activities to control RA (13). The difference in the treatment for infectious diseases is possible to be responsible for that in the level of ACPA though the treatment information to infectious diseases was not included in the questionnaire.

The production of ACPA initiates conversion of arginine to citrulline on peptides, which leads to high-affinity binding to shared major histocompatibility complex epitopes on antigen-presenting cells (10). RA has been shown to consist of two different disease subsets based on the presence of ACPA, seropositive or seronegative (11). However, the difference in the development of RA between ACPA-positive and ACPA-negative RA is still unknown. The seropositivity is associated with more phenotypic severity of RA joint inflammation (10). Circulating ACPA can be detected up to 10 years before clinical symptoms (14), indicating the role of the adaptive immune system in pathogenesis of the ACPA-positive RA. Two autoantibodies, ACPA and RF, are known and clinically used to know the activity and prognosis of RA $(15,16)$. The present study showed that there is a significant correlation between the titer of ACPA and RF, but the significant inverse relation to past infectious diseases is found with ACPA but not with RF, indicating that past infectious diseases may be associated specifically with the production of ACPA.

Recent studies have examined the role of ACPA in the pathogenesis of RA (10). Protein citrullination is an essential step in the initiation of the autoimmune response in RA $(17,18)$. Citrullination is the posttranslational deamination of arginine residues to citrullines, catalyzed by the peptidylarginine deiminases (PADs) which is affected by various environmental triggers $(19,20)$. In genetically disease-susceptable individuals, through antigen presentation, ACPA might be induced as an autoantibody against citrullinated proteins (21). The shared epitope alleles such as $H L A-D R B 1^{*} 0401$ are known to be associated with the ACPA-production $(22,23)$. Thereafter, the interaction of citrullinated proteins and ACPA has an important role in inducing activation of inflammatory cells and cytokine production which contribute the inflammatory and destructive response of RA joint (24). Thus, the positivity of ACPA is associated with more phenotypic severity of RA. On the other hand, there is little information about the mechanism of the development of ACPA-negative RA.
The mechanism of the low level of ACPA in patients with histories of infectious diseases shown in this study is unclear. In this study, we suggest two possibilities for the reason as follows. First, repeated infections may result in the production of unknown autoantibody. Previous reports showed the relation of infections such as Parvovirus B19, Epstein-Barr virus, mycoplasma, and enteric bacteria to trigger and development of RA $(25,26)$. Rheumatic fever is an illness caused by an autoimmune response to pharyngitis caused by a bacterial infection with group A streptococcus and affects the heart, brain, skin and joints (27). Thus, infectious diseases are possible to contribute to the initiation and perpetuation of joint inflammation in various rheumatic diseases. Moreover, we previously reported that neutrophils are a source of autoantigens such as defensins and cathepsin $\mathrm{G}$ and induce autoimmune response $(28,29)$. Thus, the production of autoantibody via molecular mimicry to microorganisms may be responsible, at least in part, for pathogenesis of RA patients with low levels of ACPA. Second, there is a possibility that a factor which can suppress ACPA production is produced by repeated infections. Neutrophils are crucial for protecting us from infections, especially bacterial infections by releasing antimicrobial molecules (30). Recent studies have shown that neutrophils can release nuclear chromatin lined with toxic protein in infectious regions, which is called neutrophil extracellular traps (NETs) that can be antimicrobial $(31,32)$. In NETs released from neutrophils, citrullinated proteins and PADs have been shown to be highly expressed $(32,33)$. Of PADs, PAD4 is the key enzyme that orchestrates the nuclear explosion of NETs and is found in neutrophils and the rheumatic joint $(34,35)$. Recent reports showed that anti-PAD4 autoantibodies are detected in sera from patients with RA (36), and that they can suppress the enzymatic activity of PAD4, resulting in the inhibition of PAD4-mediated citrullination (37). These results raise a possibility that the anti-PAD4 autoantibodies are produced against PADs in citrullinated NETs by repeated infections, and suppress the activity of PAD4 resulting in the suppression of citrullination and ACPA production in RA patients. Results observed in this study that significantly low levels of ACPA were detected in RA patients with neutrophil-related infections, i.e., bacterial infections (otitis media, tonsillitis, and urinary cystitis) rather than with viral infections (herpes, measles, and chickenpox) may support this hypothesis. A previous report showed that recent infections in gastrointestinal and urogenital tract but not respiratory tract are associated with a significantly lowered risk of RA suggesting that certain infections may could diminish the risk of RA via changes in the gut microbiome (38). Further studies are needed to clarify the mechanism of low levels of ACPA in RA patients with past infectious diseases. 
In the present study, there is no difference in the level of ACPA among smoking history or periodontitis status. Since smoking and periodontitis are well-established triggers of peptide citrullination in the presence of HLA-DRB1 shared epitope alleles $(39,40)$, they may lead to high level of ACPA. In this study, the number of current smokers is a few because the percentage of female is much more than that of male. Thus, the present study may include a biased population. Investigations for more patients and precise smoking history such as pack years for all former or current smokers are needed to clarify the relation of smoking with the level of ACPA. For periodontitis, there are conflicting views on the relationship between periodontitis and RA (41). Recent epidemiological data have not demonstrated a clear relationship between periodontitis and RA (42). Thus, the relation of ACPA production and periodontitis is still now controversial. In this study, periodontitis status was examined by the questionnaire to patients with RA. The status should have been examined by medical examination by a dentist.

The present study had several limitations. Since the number of subjects was relatively small and insufficient, large-scale studies should be needed. In this study, the relation of joint inflammation and ACPA was not shown because the activity of joint inflammations such as DAS28 was not measured. Moreover, there is no information about the cause of microorganisms because the information of histories of infectious diseases is limited by the result of the questionnaire to patients with RA. Although the time interval from onset of infectious diseases to detection of ACPA is an important factor, questions about the time of infectious diseases had not been included in the questionnaire. A clinical research to determine the relation between precise histories of infectious diseases and ACPA is now under investigation in our laboratory.

\section{CONCLUSION}

This study revealed that RA patients with past histories of infectious diseases are more likely to have the low level of ACPA than patients without them. We showed that bacterial infections may be related to the low ACPA, suggesting that neutrophils may be responsible for the result by their autoimmune response. Our results raise the possibility that infectious diseases are related to the initiation and perpetuation in ACPA-negative RA by producing some other antibodies.

\section{ETHICS AND CONSENT TO PARTICIPATE}

The study protocol was approved by the Tokushima University Hospital Research Ethics Board (No. 3190). All patients provided written informed consent to participate.

\section{CONFLICT OF INTERESTS}

The authors declare that they have no conflict of interest to declare.

\section{ACKNOWLEDGEMENTS}

The authors thank Ms. Yayoi Tagawa for her valuable secretarial support.

\section{REFERENCES}

1. Shimizu T, Tani K, Hase K, Ogawa H, Huang L, Shinomiya F, Sone S. CD13/aminopeptidase N-induced lymphocyte involvement in inflamed joints of rheumatoid arthritis. Arthritis Rheum. 46 : 2330-8, 2002

2. Tani K, Shimizu T, Motoki Y, Sone S. Chemokines in synovial inflammation in rheumatoid arthritis : basic and clinical aspects. Mod Rheumatol 12(2) : 93-9, 2002

3. Paul BJ, Kandy HI, Krishnan V. Pre-rheumatoid arthritis and its prevention. Eur J Rheumatol 4(2) : 161-5, 2017

4. Zamanpoor M. The genetic pathogenesis, diagnosis and therapeutic insight of rheumatoid arthritis. Clin Genet 95(5) : 547-57, 2019

5. Liao KP, Alfredsson L, Karlson EW. Environmental influences on risk for rheumatoid arthritis. Curr Opin Rheumatol 21(3) : 279-83, 2009

6. Honda K, Littman DR. The microbiota in adaptive immune homeostasis and disease. Nature 7-535(7610) : 75-84, 2016

7. Yuasa S, Yamaguchi H , Nakanishi Y , Kawaminami S, Tabata R, Shimizu N, Kohno M, Shimizu T, Miyata J, Nakayama M, Kishi J, Toyoda Y, Nishioka Y, Tani K. Treatment responses and their predictors in patients with rheumatoid arthritis treated with biological agents. J Med Invest 60 : 77-90, 2013

8. van der Linden MP, Knevel R, Huizinga TW, van der Helmvan Mil AH. Classification of rheumatoid arthritis : comparison of the 1987 American College of Rheumatology criteria and the 2010 American College of Rheumatology/European League Against Rheumatism criteria. Arthritis Rheum 63(1) : 37-42, 2011

9. de Brito Rocha S, Baldo DC, Andrade LEC. Clinical and pathophysiologic relevance of autoantibodies in rheumatoid arthritis. Ann Rheum Dis 70(1) : 128-33, 2011

10. van de Stadt LA, van der Horst AR, de Koning MH, Bos WH, Wolbink GJ, van de Stadt RJ, Pruijn GJ, Dijkmans BA, van Schaardenburg D, Hamann D. The extent of the anti-citrullinated protein antibody repertoire is associated with arthritis development in patients with seropositive arthralgia. Ann Rheum Dis 70(1) : 128-33, 2011

11. Willemze A, Böhringer S, Knevel R, Levarht EW, StoekenRijsbergen G, Houwing-Duistermaat JJ, van der Helm-van Mil AH, Huizinga TW, Toes RE, Trouw LA. The ACPA recognition profile and subgrouping of ACPA-positive RA patients. Ann Rheum Dis 71(2) : 268-74, 2012

12. Arnett FC, Edworthy SM, Bloch DA, McShane DJ, Fries JF, Cooper NS, Healey LA, Kaplan SR, Liang MH, Luthra HS, Medsger TA, Mitchell DM, Neustadt DH, Pinals RS, Schaller JG, Sharp JT, Wilder RL, Hunder GG. The American Rheumatism Association 1987 revised criteria for the classification of rheumatoid arthritis. Arthritis Rheum 31(3) : 315-24, 1988

13. Heydari-Kamjani M, Demory Beckler M, Kesselman MM. Reconsidering the Use of Minocycline in the Preliminary Treatment Regime of Rheumatoid Arthritis. Cureus. 11(8) : e5351, 2019.

14. Darrah E, Andrade F. Rheumatoid arthritis and citrullination. Curr Opin Rheumatol 30(1) : 72-78, 2018

15. Pedersen M, Jacobsen S, Klarlund M, Pedersen BV, Wiik A, Wohlfahrt J, Frisch M. Environmental risk factors differ between rheumatoid arthritis with and without auto-antibodies against cyclic citrullinated peptides. Arthritis Res Ther 8(4) : R133, 2006

16. Klareskog L, Widhe M, Hermansson M, Rönnelid J. Antibodies to citrullinated proteins in arthritis : pathology and promise. Curr Opin Rheumatol 20(3) : 300-5, 2008 
17. De Rycke L, Nicholas AP, Cantaert T, Kruithof E, Echols JD, Vandekerckhove B, Veys EM, De Keyser F, Baeten D. Synovial intracellular citrullinated proteins colocalizing with peptidyl arginine deiminase as pathophysiologically relevant antigenic determinants of rheumatoid arthritis-specific humoral autoimmunity. Arthritis Rheum $52(8):$ 2323-30, 2005

18. Fisher BA, Venables PJ. Inhibiting citrullination in rheumatoid arthritis : taking fuel from the fire. Arthritis Res Ther 14(1) : 108-9, 2012

19. Foulquier C, Sebbag M, Clavel C, Chapuy-Regaud S, Al Badine R, Méchin MC, Vincent C, Nachat R, Yamada M, Takahara H, Simon M, Guerrin M, Serre G. Peptidyl arginine deiminase type 2 (PAD-2) and PAD-4 but not PAD-1, PAD-3, and PAD- 6 are expressed in rheumatoid arthritis synovium in close association with tissue inflammation. Arthritis Rheum 56(11) : 3541-53, 2007

20. Engström M, Eriksson K, Lee L, Hermansson M, Johansson A, Nicholas AP, Gerasimcik N, Lundberg K, Klareskog L, Catrina AI, Yucel-Lindberg T. Increased citrullination and expression of peptidylarginine deiminases independently of $\mathrm{P}$. gingivalis and A. actinomycetemcomitans in gingival tissue of patients with periodontitis. J Transl Med 16(1) : 21427, 2018

21. Valesini G, Gerardi MC, Iannuccelli C, Pacucci VA, Pendolino M, Shoenfeld Y. Citrullination and autoimmunity. Autoimmun Rev 14(6) : 490-7, 2015

22. Diaz-Gallo LM, Ramsköld D, Shchetynsky K, Folkersen L, Chemin K, Brynedal B, Uebe S, Okada Y, Alfredsson L, Klareskog L, Padyukov L. Systematic approach demonstrates enrichment of multiple interactions between non$H L A$ risk variants and $H L A-D R B 1$ risk alleles in rheumatoid arthritis. Ann Rheum Dis 77(10) : 1454-62, 2018

23. Ronninger M, Seddighzadeh M, Eike MC, Plant D, Daha NA, Skinningsrud B, Worthington J, Kvien TK, Toes RE, Lie BA, Alfredsson L, Padyukov L. Interaction analysis between HLA-DRB1 shared epitope alleles and MHC class II transactivator CIITA gene with regard to risk of rheumatoid arthritis. PLoS One 7(3) : e32861, 2012

24. Elliott SE, Kongpachith S, Lingampalli N, Adamska JZ, Cannon BJ, Mao R, Blum LK, Robinson WH. Affinity maturation drives epitope spreading and generation of proinflammatory anti-citrullinated protein antibodies in rheumatoid arthritis. Arthritis Rheumatol 70(12) : 194658,2018

25. Deane KD, Demoruelle MK, Kelmenson LB, Kuhn KA, Norris JM, Holers VM. Genetic and environmental risk factors for rheumatoid arthritis. Best Pract Res Clin Rheumatol 31(1) : 3-18, 2017

26. Kudaeva FM, Speechley MR, Pope JE. A systematic review of viral exposures as a risk for rheumatoid arthritis. Semin Arthritis Rheum 48(4) : 587-96, 2019

27. Cannon JW, Abouzeid M, de Klerk N, Dibben C, Carapetis JR, Katzenellenbogen JM. Environmental and social determinants of acute rheumatic fever : a longitudinal cohort study. Epidemiol Infect 147 : e79, 2019

28. Tani K, Murphy WJ, Chertov O, Salcedo R, Koh CY, Utsunomiya I, Funakoshi S, Asai O, Herrmann SH, Wang JM, Kwak LW, Oppenheim JJ. Defensins act as potent adjuvants that promote cellular and humoral immune responses in mice to a lymphoma idiotype and carrier antigens. Int Immunol $12: 691-700,2000$

29. Tani K, Murphy WJ, Chertov O, Oppenheim JJ, Wang JM. The neutrophil granule protein cathepsin $\mathrm{G}$ activates murine $\mathrm{T}$ lymphocytes and up-regulates antigen-specific Ig production in mice. Biochem Biophys Res Comun 282 : 9716,2001

30. Chertov O, Ueda H, Xu LL, Tani K, Murphy WJ, Wang JM, Howard OM, Sayers TJ, Oppenheim JJ. Identification of human neutrophil-derived cathepsin G and azurocidin/CAP37 as chemoattractants for mononuclear cells and neutrophils. J Exp Med 186(5) : 739-47, 1997

31. Stobernack T, du Teil Espina M, Mulder LM, Palma Medina LM, Piebenga DR, Gabarrini G, Zhao X, Janssen KMJ, Hulzebos J, Brouwer E, Sura T, Becher D, van Winkelhoff AJ, Götz F, Otto A, Westra J, van Dijl JM. A secreted bacterial peptidylarginine deiminase can neutralize human innate immune defenses. MBio 9(5) : e01704-18, 2018

32. Wright HL, Moots RJ, Edwards SW. The multifactorial role of neutrophils in rheumatoid arthritis. Nat Rev Rheumatol. 10(10) : 593-601, 2014

33. Apel F, Zychlinsky A, Kenny EF. The role of neutrophil extracellular traps in rheumatic diseases. Nat Rev Rheumatol 14(8) : 467-75, 2018

34. Wong SL, Wagner DD. Peptidylarginine deiminase 4 : a nuclear button triggering neutrophil extracellular traps in inflammatory diseases and aging. FASEB J fj201800691R, 2018

35. O'Neil LJ, Kaplan MJ. Neutrophils in rheumatoid arthritis : Breaking immune tolerance and fueling disease. Trends Mol Med 25(3) : 215-27, 2019

36. Pollmann S, Stensland M, Halvorsen EH, Sollid LM, Kvien TK, Fleckenstein B, Molberg O. Anti-PAD4 autoantibodies in rheumatoid arthritis : levels in serum over time and impact on PAD4 activity as measured with a small synthetic substrate. Rheumatol Int 32(5) : 1271-6, 2012

37. Auger I, Martin M, Balandraud N, Roudier J. Rheumatoid arthritis-specific autoantibodies to peptidyl arginine deiminase type 4 inhibit citrullination of fibrinogen. Arthritis Rheum 62(1) : 126-31, 2010

38. Sandberg ME, Bengtsson C, Klareskog L, Alfredsson L, Saevarsdottir S. Recent infections are associated with decreased risk of rheumatoid arthritis : a population-based case-control study. Ann Rheum Dis 74 (5) : 904-7, 2015.

39. Karlson EW, Chang SC, Cui J, Chibnik LB, Fraser PA, De Vivo I, Costenbader KH. Gene-environment interaction between HLA-DRB1 shared epitope and heavy cigarette smoking in predicting incident rheumatoid arthritis. Ann Rheum Dis 69(1) : 54-60, 2010

40. Corrêa MG, Sacchetti SB, Ribeiro FV, Pimentel SP, Casarin RC, Cirano FR, Casati MZ. Periodontitis increases rheumatic factor serum levels and citrullinated proteins in gingival tissues and alter cytokine balance in arthritic rats. PLoS One 12(3) : e0174442, 2017

41. Potempa J, Mydel P, Kozieel J. The case for periodontitis in the pathogenesis of rheumatoid arthritis. Nat Rev Rheumatol 13(10) : 606-20, 2017

42. Malmström V, Catrina AI, Klareskog L. The immunopathogenesis of seropositive rheumatoid arthritis : from triggering to targeting. Nat Rev Immunol 17(1) : 60-75, 2017 